\title{
DIAGNOSTIC REAGENTS AND THEIR USES IN THE DIAGNOSIS OF INFECTIOUS DISEASES.*
}

BY F. E. STEWART, PH.G., M.D., PHAR.D.

In my paper read before the Scientific Section of the A. Ph. A., at the San Francisco meeting, August, 1915, entitled "Principles Underlying the Use of Vaccines, Bacterins, Antitoxins and Immune Serums as Agents for the Prevention and Cure of Infectious Diseases," attention was called to the properties of immune serum, that is, serum from an animal immunized against an infective agent.

Immune serum manifests four specific actions assumed to be due to the presence of antibodies, namely: $(a)$ antitoxic action; $(b)$ bactericidal and lysogenic action; $(c)$ opsonic action; $(d)$ agglutinating and closely allied precipitating action. The antitoxic action is due to the presence of antitoxin. The bactericidal and lysogenic is assumed to be due to the presence of an antibody to which the name bacteriolysin has been applied. ${ }^{1}$ The opsonic action is assumed to be due to opsonins. The word opsonin is from Greek opsono, to prepare food for. The specific opsonin developed in the blood serum during the process of immunization has the property of preparing the bacteria for ingestion and digestion by the leucocytes, or white corpuscles of the blood. When a small quantity of immune serum is added to a suspension of the corresponding bacterium, the organism becomes agglutinated into clumps and motility is suspended or destroyed. This action is assumed to be due to the presence of agghtinins. Advantage is taken of the phenomena in diagnosing typhoid fever, as will appear later. The immune serum may not only cause agglutination, but, when added to the filtrate of a culture of the corresponding bacterium, may produce a cloudiness and afterwards a precipitate.

Antigen.-An antigen is a protein substance which, introduced into the animal body, stimulates the body cells to produce antibodies. Practically any protein substance may serve as antigen.

Character of Antigens.-There are two views on this subject. Vaughan believes that the various so-called antibodies are merely manifestations of enzyme action. He points out that when any protein substance, either living or dead, is introduced into the animal body the body cells are stimulated to produce proteolytic enzymes, or digestive ferments, which have the power of digesting and destroying the protein substance referred to. When a protein substance is taken into the alimentary canal and digested by the various enzymes prepared by the glands emptying their contents into this canal, the digestion is called enteral. When a protein substance is injected into the tissues, the body cells at the point of injection are stimulated to produce specific digestive enzymes; this digestion is known as parenteral digestion. Vaughan explains infection and immunity on this basis, as stated in my former article. Certain body cells, having acquired the power of producing enzymes or digestive ferments resulting from an infection, are in position to respond promptly when again stimulated by an attack of an infective agent, and in this way the body acquires immunity of greater or less

* Read before Scientific Section, A. Ph. A., Atlantic City meeting, 1916.

${ }^{1}$ This action is due to the combined effect of two substances, amboceptor and complement. There is some question as to whether or not the bactericidal amboceptor is identical with the complement-fixing amboceptor concerned in the Wassermann reaction. For the purposes of this paper a final answer is unessential. 
degree and duration against subsequent attacks. Immunity following an attack of typhoid fever and other infectious diseases is thus accounted for. It will thus be seen that the terms "antibody" and "enzyme" practically represent the same principles.

Bacteriolysis.-Bacteriolysis is assumed to be due to the production in the blood of the immunized individual of an antibody to which the name bacteriolysin has been given. According to Vaughan, bacteriolysis is due to the digestive action of a proteolytic enzyme produced by the body cells in response to stimulation by the appropriate protein. According to the same authority, all enzymes are made up of two factors, namely: complement and amboceptor. It is the function of the complement to digest the antigen. This it cannot do until the antigen is acted upon or sensitized by the amboceptor. What really occurs as a result of introducing a protein substance into the animal body is the production, not of an enzyme, but of the specific part of an enzyme, namely, the amboceptor. Complement is not specific-it exists normally in the blood of all animals, and is practically the same, no matter from what source derived.

We therefore have in the production of bacteriolysis three factors, namely: the bacterium, the specific amboceptor or antibady, and the complement. When these three factors react, bacteriolysis occurs. (See Fig. 1.) In this reaction the complement is absorbed or fixed by its attachment to the sensitized bacteria.
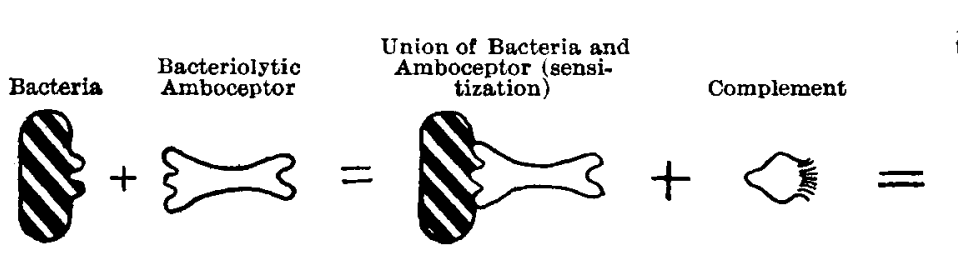
A ttaching of Complement to the Sensitized Bacteria. Bacteriolysis will Result

FIXATION OF COMPLEMENT BY BACTERIOLYSIS

Hemolysin.--In a similar manner when an animal, say a rabbit, is immunized against the red corpuscles of the sheep, the blood serum of such an animal possesses lysogenic action for the red corpuscles of the sheep's blood, but does not possess lysogenic action toward the red corpuscles of any other kind of animal's blood. This lysogenic action in the case of red blood corpuscles is known as hemolysis, and it is assumed by some that the cause of the hemolysis is due to the presence of another antibody, namely: a peculiar specific principle in the immune serum to which the name specific hemolysis has been given. But this specific hemolysin alone will not cause hemolysis. Hemolysis is the result of the action of three factors: $i$. e., red corpuscles, specific hemolysin and complement. These three react, causing the disintegration or breaking down of the stroma of the red corpuscles, and liberates the hemoglobin into the surrounding fluid, which becomes a clear, red, transparent solution instead of the opaque suspension of red corpuscles. (See Fig. 2.) In this reaction the complement is absorbed or fixed by its attachment to the sensitized erythrocyte.

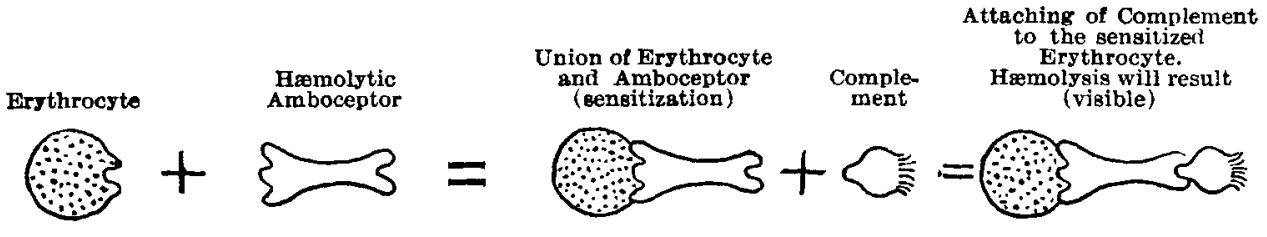


Precipitin Reaction.-If any unformed protein substance is introduced into the body of an animal, the blood serum of such an animal, when added to a solution of the same protein, will produce a precipitin. This phenomenon is assumed to be due to a specific substance in the serum formed during the process of immunization, to which the name Precipitin has been given. Now, if to a mixture of this immune serum and the precipitate referred to, complement is added, no visible manifestation will occur. However, the complement will be fixed by the precipitate. (See Fig. 3.)

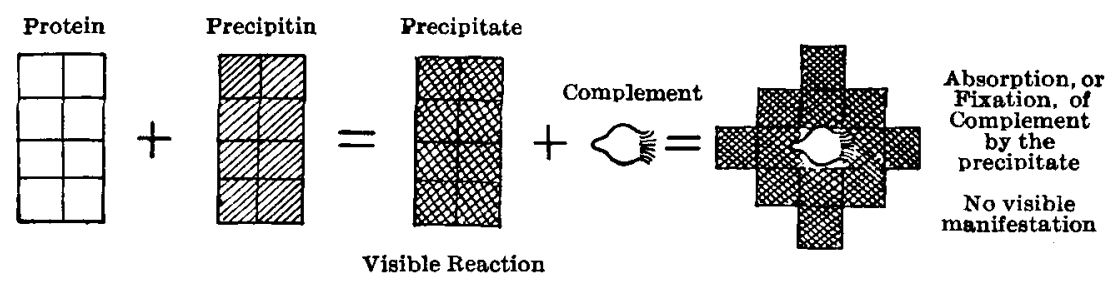

FIXATION OF COMPLEMENT BY PRECIPITIN REACTION

Bordet-Gengou Phenomenon.-We are now in a position to consider the Bordet-Gengou phenomenon of complement fixation upon which is based the Wassermann reaction and the several modifications of the same used in the diagnosis of syphilis.

In the above three figures it will be noted that the complement united with the antigen-antibody combination and, therefore, became fixed. This reaction, however, is invisible and means must be had to determine that it has or has not taken place. For this purpose a so-called hemolytic system is employed. Let us consider for a moment that we have placed a suspension of antigen, antibody and complement, for example. Place bacteria, bacteriolytic amboceptor and complement in a test-tube in the incubator. Bacteriolysis occurs during incubation. Now, if we add to the test-tube a hemolytic system (erythrocytes and hemolytic amboceptor), and again incubate, no hemolysis will occur because the complement has been used up in the bacteriolysis which preceded. (See Fig. 4.)

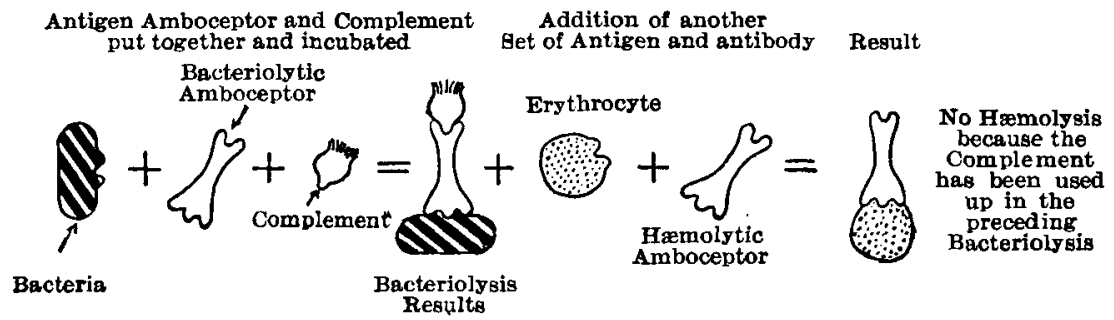

ILLUSTRATION OF PHENOMENA OF BORDET AND GENGOU

If the bacteriolytic amboceptor had been omitted, bacteriolysis would not have occurred during the first incubation. This would have been shown by the hemolysis, which in that case would have followed the second incubation because the complement, which could not have been fixed by the bacteria in the absence of bacteriolytic amboceptor, was free to unite with the erythrocytes and hemolytic amboceptor and break down the red blood cells liberating the hemoglobin (a reaction which is plainly visible).

This phenomenon was discovered by Bordet and Gengou in 1901. It depends 
upon the fact that when an antigen is mixed with its inactivated ${ }^{2}$ antiserum, in the presence of complement, the complement is fixed by the antigen combination and disappears from the mixture. If such a mixture is allowed to stand at a suitable temperature for an hour or more, and to it is added a suspension of erythrocytes, together with a suitable quantity of inactivated hemolytic amboceptor, hemolysis will not take place, as has already been pointed out, since there is no free complement present to complete the hemolytic system. If, on the other hand, the original mixture contains no antibody for the antigen used, the complement present is not fixed and is available for the activation of the hemolytic serum later added.

The reaction depends upon the fact that neither antigen alone, nor amboceptor (antibody) alone, can fix complement, but that this fixation is accomplished only by the antigen-amboceptor complement. Any specific amboceptor can be determined by this method, provided the homologous or stimulating antigen is used; and, on the other hand, by the use of a known antibody a suggested antigen may be determined.

This indirect method of determining the presence of a specific reaction between antigen and antibody has been extensively applied to various infectious diseases with more or less success. As stated by Kolmer, ${ }^{3}$ the complement-fixation methods have their great value, and are probably best known, in the serum diagnosis of syphilis,-the biologic syphilitic reaction of Wassermann, Neisser, Bruch, and Detre.

The Wassermann Reaction.-In their original experiments Wassermann and his collaborators used salt-solution extracts of syphilitic organs. Various modifications have been suggested, and at present the methods of preparing antigens may be divided into seven different classes as follows:

(1) Aqueous extract of syphilitic livers.

(2) Alcoholic extracts of syphilitic liver.

(3) Alcoholic extracts of normal organs.

(4) Alcoholic extracts of normal organs re-enforced with cholesterin.

(5) Acetone-insoluble lipoids.

(6) Lecithin and cholesterin.

(7) Aqueous extracts of pallidum culture.

It is evident from the above that the term "antigen," as originally used in the Wassermann reaction, is a misnomer. The only specific biological antigen is a pure culture of Treponema pallidum (Spirochata pallidum).

In performing the test by the original Wassermann system, five different factors are required, $i . e .:$ (1) antigen, which in the original test consisted of a salt solution of syphilitic organ, as already stated; (2) the patient's serum ; (3) complement (fresh guinea-pig's serum); (4) hemolytic amboceptor, $i$. e., blood from a rabbit immunized against the red corpuscles of a sheep ; (5) red corpuscles from the blood of a sheep. When the syphilitic antigen, suspected serum and complement are incubated together the complement will or will not be fixed, depending upon whether or not the suspected serum contains syphilitic amboceptor. If the serum contains syphilitic amboceptor, it will fix the complement. However, as there is no visible manifestation of this when it occurs, it becomes necessary to have an indicator. This indicator consists of the other two factors, namely: a

${ }^{2}$ Fresh serum heated to from $55^{\circ}$ to $56^{\circ} \mathrm{C}$, to destroy the complement. This process is called "inactivation," and the heated serum is called "inactivated" serum.

" Infection, Immunity and Specific Therapy," John A. Kolmer, M.D., Ph.D., W. B. Saunders Co,, Phila., Publishers, 1915. 
suspension of sheep corpuscles and serum from a rabbit previously immunized against sheep corpuscles, and therefore containing hemolytic sheep amboceptor. This is added to the mixture in the test-tube. If, following the addition of this second set of antigen and amboceptor, $i$. e., red blood corpuscles of the sheep and serum of rabbit immunized against sheep corpuscles, hemolysis (lysis of the sheep corpuscles) occurs, it shows that the complement was free in the mixture in the test-tube, and, therefore, the suspected serum contains no syphilitic amboceptor. If, on the contrary, hemolysis does not occur, it is evident that the suspected serum contains syphilitic amboceptor, and that the reaction did occur in the test-tube, resulting in the fixing of the complement by the antigen-amboceptor combination. As at present carried out any one of the above-mentioned antigens may be employed in the reaction, the most common probably being No. 5-Acetone-insoluble lipoids - as recommended by Noguchi.

The Noguchi Modification of the Wassermann Reaction.-Among the large number of modifications of the original syphilis reaction that have been devised, that of Noguchi is acknowledged to be of distinct value.

In presenting his modification, Noguchi" says that "the chief cause why the original method of Wassermann was so difficult to carry out is because in that system the reagents are so unstable and associated with many other undesirable side actions that these must be used soon after being prepared." He calls attention to the fact that these difficulties are inherent to most of the modifications described.

To overcome these difficulties Noguchi has suggested a method whereby the preparation of the most important and difficult reagents is done by competent laboratory workers in a regular biological laboratory and distributed among those who understand how to use the apparatus. The reagents for making the test are as follows:

Several 1-Cc. pipettes, graduated to $0.1 \mathrm{Cc}$, are required; also two $10-\mathrm{Cc}$. pipettes graduated to $0.1 \mathrm{Cc}$., and several 1 - Cc. pipettes graduated to $0.01 \mathrm{Cc}$. A number of small test-tubes are also required, the best dimensions being $10 \times 1 \mathrm{~cm}$. Two of these tubes are necessary for each test, and four tubes for controls in each series of tests. Of course the total number needed will depend upon the amount of work to be done. In addition to the above apparatus, a number of larger testtubes, or very small flasks, for mixing the blood suspension, a number of larger flasks or bottles as containers of physiological salt solution are required; also glass tubing, about $4 \mathrm{~mm}$, in bore, for making capillary pipettes. A few test-tube racks with two parallel rows of holes must be provided; also a pair of scissors, a paraffin pencil, centrifuge and incubator. This apparatus must be chemically clean.

The reagents employed are: (1) patient's serum; (2) serum from individual known to be in health; (3) serum from individual known to be syphilitic; (4) suspension of red corpuscles from the human blood ; 5 ) diluted antigen ; (6) complement; (7) amboceptor; (8) physiological salt solution.

The blood required may be obtained by puncturing the finger, or in small children the lobe of the ear should be punctured. The blood will come in drops. When the finger is selected, it should be tightly squeezed in such a manner as to drive the blood to the extremity, or bound with a narrow bandage starting at the proximal end, to accomplish the same object. A prick is then made with a

'Serum Diagnosis of Syphilis and Luetin Reaction, by Hideyo Noguchi, M.D., M.Sc., associate member of the Rockefeller Institute for Medical Research. Published by J. B. Lippincott Company, Philadelphia (third ed.), 1912. 
sterile needle, as illustrated in the cut. For collecting the blood, Wright's capsules are the best suited. The blood is collected by touching the curved end of the needle as it oozes from the puncture. When sufficient blood has been collected the straight, empty capillary end of the capsule is sealed with a flame. When cool, the blood is driven ${ }^{5}$ from the bent end of the capsule to the straight end, then the bent end is also sealed with a flame. By this method the capsule can be sealed without heating the blood.

The capsule is then set asidc to permit the clotting of the blood, or the process is hastened by centrifugalization.

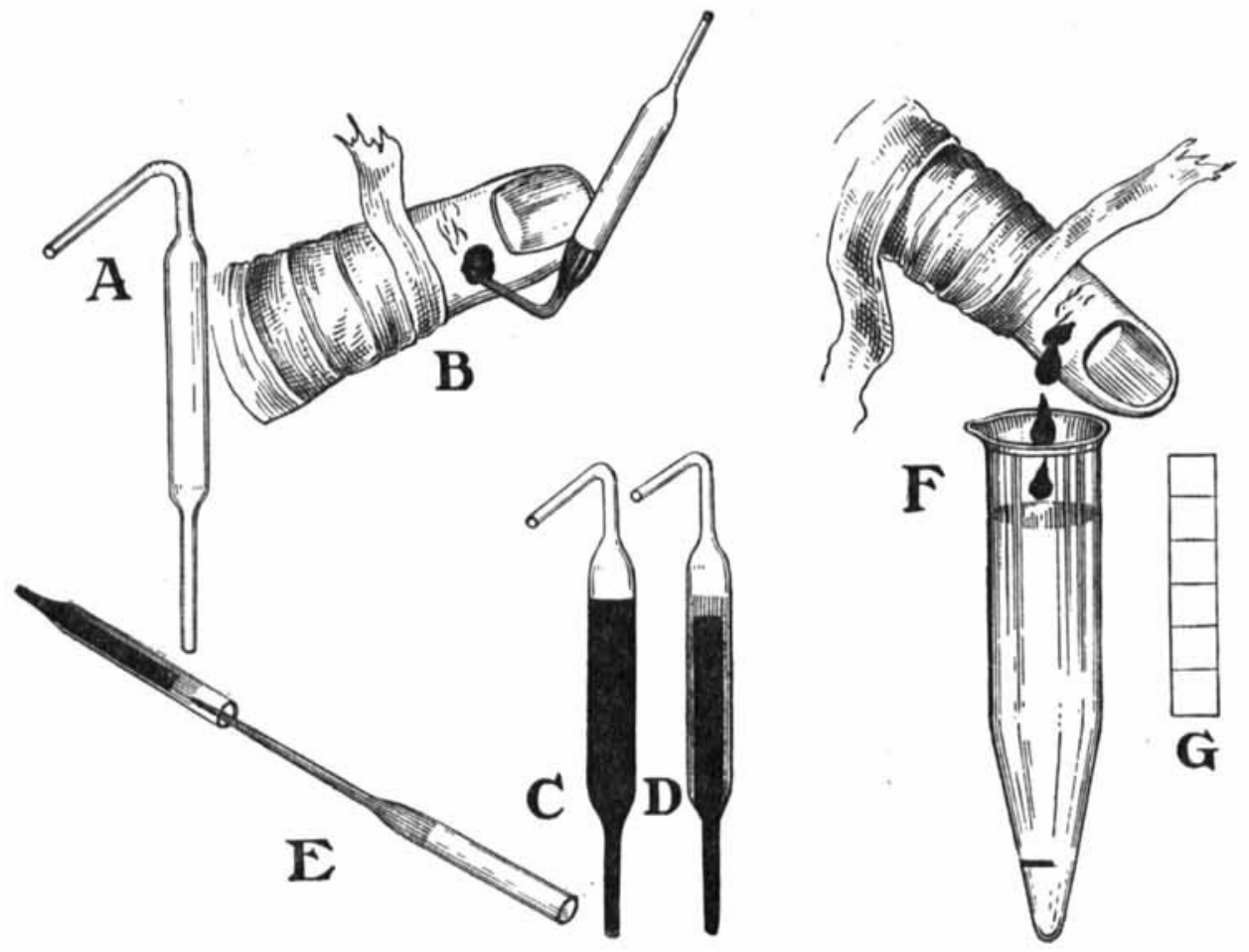

$A$ represents the capsule for collecting blood from the patient. $B$ represents the method of obtaining the patient's blood. $C$ represents the blood after it has been shaken down to the straight end of the capsule. The capsule is then set aside to allow the serum to separate, or it may be centrifugalized. $D$ represents the clotted blood and the separated serum. $E$, capillary pipettes used to collect serum and drop it into test-tube. $F$ illustrates the procedure for obtaining blood for the suspension of human red blood-corpuscles. $G$ represents the antihuman amboceptor paper, which may be obtained from the regular biological laboratories.

The suspension of red corpuscles can be prepared with the blood of the patient being examined. The standard amount of the suspension required is $1 \mathrm{Cc}$. of a one percent, or $0.1 \mathrm{Cc}$. of a ten-percent for each tube. Thus, if $1 \mathrm{Cc}$. of blood is taken from the patient, it will supply enough corpuscles to distribute in 100 test-tubes. The blood from one patient will suffice for preparing suspension for testing several patients.

"Supposing one wishes to make 1 Cc., sufficient for 10 tubes (or less), including controls. Take an ordinary centrifuge tube, put into it with a graduated pipette $1 \mathrm{Cc}$. of sodium chloride $(0.9$ percent) solution. Mark the tube at the surface of the liquid with a paraffin pencil or file. Now fill up with sodium

${ }^{\circ}$ Shake the tube the same as a clinical thermometer is shaken. 
chloride solution to within half inch of the top and mark at the surface of the liquid. Draw out $0.1 \mathrm{Cc}$. and discard it. Allow blood to drop into the tube until it reaches the last mark on the tube. Centrifugalize and decant the supernatant fluid. Fill the tube with saline solution to the first mark, $1 \mathrm{Cc}$. This represents the suspension of washed red corpuscles in saline solution from 10 percent whole blood. $0.1 \mathrm{Cc}$. is the quantity used for each tube."

Antigen.-The regular biological laboratories furnish antigen prepared in the following manner: "Liver or heart tissue is rubbed with sand and then extracted with absolute alcohol by maceration. Ten grammes of tissues are macerated in $100 \mathrm{Cc}$. of alcohol for one week at $37^{\circ} \mathrm{C}$., shaking the container every day. The mixture is then filtered, and the filtrate evaporated to an extractive consistence and dissolved in ether until clear. Pour this solution into a large quantity of acetone. The acetone precipitates certain lipoid substances which are then collected and redissolved in methyl alcohol, in ratio of 3 percent. This constitutes the antigen solution. For use, mix one part of this with 9 parts, 0.9 percent, sodium chloride solution. This dilution should not cause hemolysis in an amount of $0.4 \mathrm{Cc}$, and $0.4 \mathrm{Cc}$. should not inhibit hemolysis. The quantity for each tube should be $0.1 \mathrm{Cc}$., containing at least 5 units."

Testing Antigen.-The concentrated antigen solution furnished by the biological laboratory should be tested in the following way:

"Dilute the concentrated alcoholic solution with 9 parts sodium chloride solution ( 0.9 percent). This makes an opalescent liquid.

Test it for: (1) Hemolytic power: 0.4 Cc. should not be hemolytic; (2) anticomplementary power: $0.4 \mathrm{Cc}$. should not inhibit hemolysis; (3) antigenic power: $0.02 \mathrm{Cc}$. must give complete inhibition with syphilitic serum.

Five units, or $0.1 \mathrm{Cc}$., of the diluted solution is to be used in each tube.

Amboceptor.- This may be obtained from the regular biological laboratories. It is prepared by repeatedly injecting washed human blood corpuscles (erythrocytes) into rabbits, at intervals of three to five days. Ten days are allowed to elapse after the last injection. The rabbits are then bled and the serum collected. Paper is now saturated with this serum and allowed to dry. The paper is cut in strips and set aside until wanted for use. In this form amboceptor will keep for a considerable length of time.

"Amboceptor paper is standardized by measuring its specific gravity. The measurement of specific activity consists in finding the amount of amboceptor necessary to cause hemolysis in $1 \mathrm{Cc}$. of a ten-percent suspension of washed human red corpuscles with $0.4 \mathrm{Cc}$. of fresh guinea-pig serum. Incubate this at a temperature of $37^{\circ} \mathrm{C}$. for one hour. The quantity of paper necessary to cause hemolysis under these conditions is known as one unit. In the syphilis test use two units."

Complement.- "Guinea-pigs are bled into a sterile. Petri dish. This can be done several hours before the tests are to be made, and the Petri dish kept in the dark at room temperature until desired for use. If the serum has not separated by the time it is wanted, place the Petri dish containing the blood into an incubator at $37^{\circ} \mathrm{C}$. for ten or fifteen minutes. Then pipette off the serum. Any corpuscles remaining in the serum must be separated by centrifugalizing. As complement rapidly deteriorates and no method has yet been devised to preserve its activity for more than a few hours, it cannot be supplied commercially. Fresh guinea-pig serum should be used, $0.04 \mathrm{Cc}$. to each tube.

Method of procedure.-Having on hand the necessary apparatus and reagents, the following procedure for making the tests is adopted: 
(1) Into each of the tubes, 1 and 1' ( see $\mathrm{H}$ ), is placed one drop of the patient's serum. Use four drops when inactivated serum is used.

(2) Into each of the tubes, 2 and $2^{\prime}$, is placed one drop of serum from an individual known to be in health. Use four drops, when inactivated serum is used.

(3) Into each of the tubes, 3 and $3^{\prime}$, is placed one drop of serum from the blood of an individual known to be syphilitic. Four drops should be used when an inactivated serum is employed. A drop of serum is represented by the figures 1-1-1.

(4) Into all the tubes is placed $0.04 \mathrm{Cc}$. of complement, i. e., fresh guineapig serum, marked 2-2-2. This quantity is readily obtained by diluting $1 \mathrm{Cc}$. - fresh guinea-pig serum with $9.0 \mathrm{Cc}$. sterile normal saline solution ( 0.9 percent). Then, $0.4 \mathrm{Cc}$. of the dilution represents $0.04 \mathrm{Cc}$. of guinea-pig serum.

(5) Into each of the tubes is placed 0.3 or $0.4 \mathrm{Cc}$. (as stated in table) sodium chloride solution ( 0.9 percent).
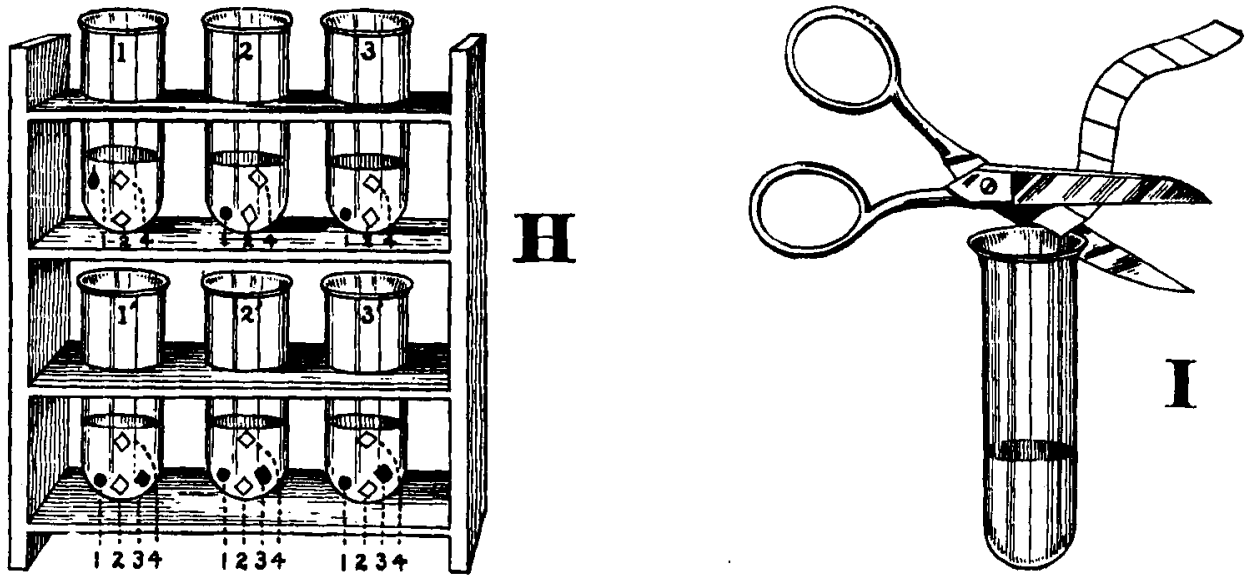

TABLE SHOWING ARRANGEMENT OF TEST-TUBES AND REAGENTS

\begin{tabular}{|c|c|c|c|c|c|c|}
\hline Tube. & $\mathrm{NaCl}$. & $\begin{array}{c}1: 10 \\
\text { Antigen. }\end{array}$ & Serum. & $\begin{array}{c}1: 10 \\
\text { Complement. }\end{array}$ & $\begin{array}{l}1: 10 \\
\text { Corp. }\end{array}$ & Amboceptor. \\
\hline 1 & 0.4 & 0 & $1 \mathrm{gtt}$. patient's & $.4 \Xi$ & .1 & 2 units \\
\hline $1^{\prime}$ & 0.3 & 0.1 & 1 gtt. patient's & $.4 \overline{\mathrm{L}}$ & .1 & 2 units \\
\hline 2 & 0.4 & $\mathbf{0}$ & 1 gtt. normal & .47 & .1 & 2 units \\
\hline $2^{\prime}$ & 0.3 & 0.1 & $1 \mathrm{gtt}$. normal & $.4 \frac{\mathrm{T}}{8}$ & .1 & 2 units \\
\hline 3 & 0.4 & $\mathbf{0}$ & $1 \mathrm{gtt}$. syphilitic & $.4 \bar{Z}$ & .1 & , 2 units \\
\hline $\mathbf{3}^{\prime}$ & 0.3 & 0.1 & 1 gtt. syphilitic & $.4 \Xi$ & .1 & 2 units \\
\hline
\end{tabular}

(6) Into each of the tubes, $1^{\prime}, 2^{\prime}$ and $3^{\prime}$, is placed $0.1 \mathrm{Cc}$. of diluted antigen (1:10) solution, represented by the figures 3-3-3.

The tubes are then placed in a water-bath at $37^{\circ} \mathrm{C}$, , the temperature of the body, for one-half hour (or in an incubator for one hour). During this time, in any tubes containing serum from a syphilitic individual, the antigen will unite with the syphilitic amboceptor (antibody) in the syphilitic serum and these two will in turn unite with the complement, fixing it. After incubation, the tubes are removed, and each tube receives $0.1 \mathrm{Cc}$. of red corpuscle suspension and one square of amboceptor paper (see I), marked 4-4-4 ( $\mathrm{H}$ ). The tubes are then returned to the incubator, where they are allowed to stand (shaking gently every 15 minutes) until hemolysis has occurred in tubes 1,2 and 3 , which are controls because they contain no antigen, and in the tube to which was added one drop of known healthy serum-that is, tube $2^{\prime}$. The tube $3^{\prime}$, containing a drop of serum 
from a known syphilitic individual, will still remain cloudy, as it was when placed in the incubator, while the tube $1^{\prime}$, containing serum from the patient, will be a bright, clear red (hemolysis), or cloudy. If the hemolysis does not occur, the reaction denotes the presence of syphilis.

Exceptions.-Serum from persons afflicted with tubercular and mixed types of leprosy, sleeping sickness and yaws may also react positively.

The application of the Noguchi system requires a certain amount of laboratory technique which can only be obtained by experience.

Complement-Fixation Tests in Other Diseases.-The use of complement-fixation tests may be applied to other diseases than syphilis. Much attention is being given to the subject in connection with various infections, such as gonorrhea, glanders, contagious abortion, typhoid fever, tuberculosis, etc. Complement fixation is also used in the standardization of immune serum.

(To be continued.)

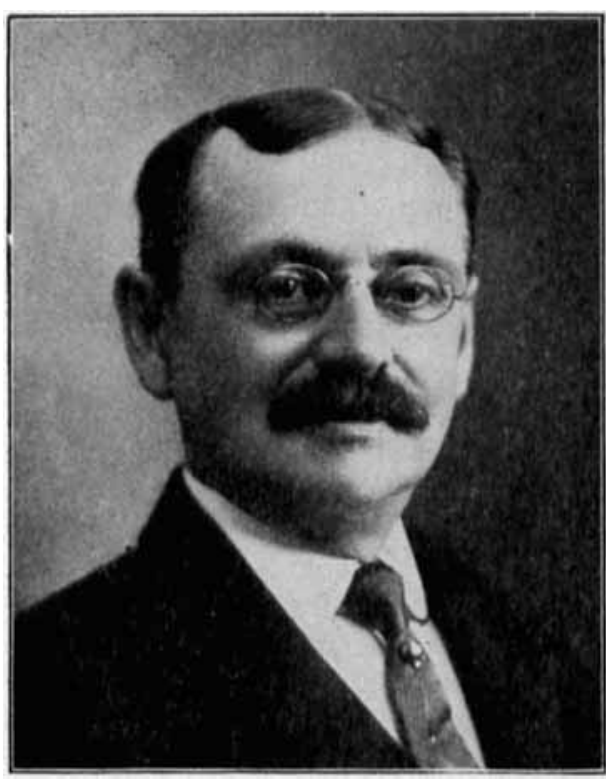

GEO. M. BERINGER, Camden, N.J. Chairman, Commit tee on Unofficial Standards.

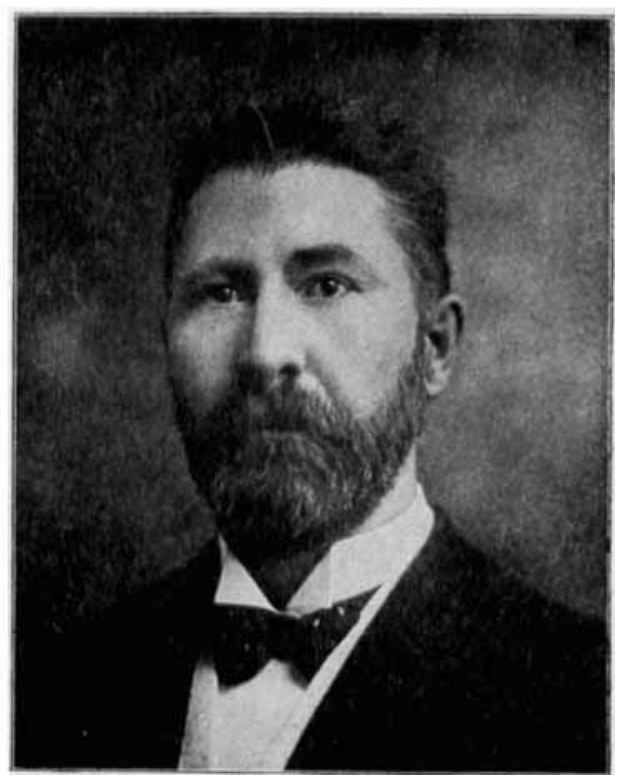

PROF. OTTO RAUBENHEIMFR

Chairman, Committee on A. Ph, A. Recipe Book. 